\title{
La justicia cotidiana y la nueva justicia laboral
}

\author{
Rodrigo Maldonado Corpus \\ Magistrado del Tribunal de Justicia Administrativa del Estado de Nuevo León, México \\ rr_maldonado@yahoo.com.mx
}

Recibido: 23/10/2017

Dictaminado: 22/02/2018

\section{Resumen}

El objetivo del presente trabajo es analizar la jurisdicción laboral desde su aparición en la Constitución del 5 de febrero de 1917, sus diversas reglamentaciones desde el 18 de agosto de 1931 cuando surge la primera Ley Federal del Trabajo, hasta la última reforma del 2012. Esto a fin de determinar si se cumplieron con los objetivos y propuestas de los Diálogos por la Justicia Cotidiana, en la reforma Constitucional al artículo 123 apartado A del 24 de febrero del año en curso, y en la iniciativa de reforma a la Ley Federal del Trabajo del 28 de abril de 2016.

Palabras clave: Jurisdicción, Juntas de Conciliación y Arbitraje, Justicia Cotidiana, Iniciativa y Reforma.

\section{The daily justice and the new labor justice}

\begin{abstract}
The objective of this paper is to analyze the labor jurisdiction since its appearance in the Constitution of February $5^{\text {th }}, 1917$, its different regulations since August $18^{\text {th }}, 1931$ - when the first Federal Labor Law arose- until the last amendment in 2012. In order to determine whether the objectives and proposals of the Dialogues for Everyday Justice were fulfilled, in the Constitutional amendment to the article 123, section A of February $24^{\text {th }}$ of the current year, and in the amendment initiative to the Federal Labor Law of April $28^{\text {th }}, 2016$.
\end{abstract}

Key words: Jurisdiction, Conciliation and Arbitration Boards, Everyday Justice, Initiative and Reform. 


\section{Sumario}

I. Leyes reglamentarias del artículo 123 Constitucional; 1.1 Antecedentes; 1.2 Ley Federal del Trabajo de 1931; 1.3 Ley Federal del Trabajo de 1970; 1.4 Reforma Laboral de 2012; II. Diálogos por la Justicia Cotidiana; 2.1 Antecedentes; 2.2 Diálogos por la Justicia Cotidiana en la Justicia Laboral; 2.2.1. Problemas específicos; 2.2.2. Soluciones propuestas; III. Iniciativas del Ejecutivo Federal en Materia Laboral derivados de la Justicia Cotidiana; 3.1. Iniciativa de Reforma Constitucional al artículo 123, apartado A; 3.1.1. Exposición de Motivos; 3.1.2. Reforma Constitucional del 24 de febrero de 1917; 3.2. Iniciativa de Reforma a la Ley Federal del Trabajo; 3.2.1. Exposición de Motivos; 3.2.2. Contenido de la Iniciativa del 28 de abril de 2016; IV. Conclusiones; Bibliografía.

"No saber lo que ha sucedido antes de nosotros, es como ser incesantemente niños".

Cicerón.

\section{Leyes reglamentarias del artículo 123 Constitucional}

Por cuestión de metodología y para una mejor comprensión del objeto de este trabajo, resulta obligado realizar un breve análisis de la legislación laboral, sus antecedentes y su estatus actual.

\subsection{Antecedentes}

Al promulgarse la Constitución Política de los Estados Unidos Mexicanos, en su artículo 123, fracción XX ya transcrita, se encomendó a las Juntas de Conciliación y Arbitraje, integradas por representantes obreros, patronales y del gobierno; la misión de resolver los conflictos que se presentaran entre obreros y patrones.

Al respecto Rafael de Pina, ${ }^{1}$ apunta que la jurisdicción mexicana del trabajo se estableció por la necesidad de sustraer al conocimiento de los tribunales comunes las cuestiones planteadas como consecuencia de las relaciones de trabajo ya que no podian ser adecuadamente resueltas; ni con la urgencia

1 De Pina, Rafael. Curso de Derecho Procesal del Trabajo. Botas, México, 1952, pp. 57 y 58. 
requerida, por lo excesivamente engorroso y dilatorio de la justicia ordinaria. Además, la presencia en los órganos de la jurisdicción laboral de un número cuantitativo igual de miembros representativos, tanto de los intereses patronales y obreros, presididos por un funcionario público; permitió que estos tribunales estuvieran en condiciones de merecer la confianza de la clase social a que pertenecen las personas llamadas a llevar ante ellos los conflictos, pues debido a la desconfianza, sobre todo del proletariado hacia los órganos del Poder Judicial, no permitía encomendarles a estos dicha función.

Es importante señalar, que con independencia con lo establecido por nuestra Constitución, la naturaleza jurídica de las Juntas causó gran polémica llegándose a considerar por parte de la Suprema Corte de Justicia de la Nación que las Juntas de Conciliación y Arbitraje, no tenían competencia constitucional para conocer de los conflictos planteados en virtud de los contratos de trabajo, ni para dictar laudos, ni ejecutarlos coactivamente; reconociéndoles únicamente capacidad conciliatoria en los conflictos colectivos, según lo estableció en la ejecutoria del 8 de marzo de 1918, denominada "Guillermo Cabrera".

Sin embargo, seis años después, la Suprema Corte de Justicia expresó un punto de vista diferente, atribuyendo a las Juntas de Conciliación y Arbitraje, la competencia necesaria para resolver tanto los conflictos colectivos de trabajo como los individuales, sin que esto pudiera implicar la violación de lo ordenado en el artículo 13 constitucional, que prohíbe juzgar a través de tribunales especiales; esto mediante la ejecutoria del 1 de febrero de 1924, denominada "La Corona". Cabe destacar, que meses después, el Pleno de la Suprema Corte de Justicia, en forma más precisa y mejor elaborada, resolvió categóricamente que las Juntas de Conciliación y Arbitraje instituían verdaderos tribunales, encargados de resolver todas aquellas cuestiones relacionadas con el contrato de trabajo, en materia colectiva o individual, y gozaban de imperio para ejecutar sus laudos; esto lo asentó, mediante la ejecutoria dictada el 21 de agosto de 1924, denominada "Compañia de Tranvías, Luz y Fuerza de Puebla, S. A."

Por lo antes expuesto, podemos aseverar, tal y como lo declaran Juan Francisco Rocha Bandala y José Fernando Franco, ${ }^{2}$ que desde aquellos días

2 Rocha Bandala, Juan Francisco y Franco, José Fernando. La Competencia en Materia Laboral. Cárdenas, Editor y Distribuidor, México, 1975, p. 156. 
ya nadie podría discutir la calidad de autoridad jurisdiccional de las Juntas de Conciliación y Arbitraje, ni su competencia para resolver asuntos laborales de carácter individual o colectivo, con todas las facultades inherentes a un verdadero Tribunal.

Asimismo, el distinguido jurista Rafael de Pina $^{3}$ nos recuerda que la reglamentación del artículo 123 de la Constitución Federal estuvo confiada en un principio a las legislaturas locales, y no fue sino hasta la reforma del 31 de Agosto de 1929, que se federalizó la Legislación Laboral del país; fundada entre otros motivos, en el incumplimiento por parte de algunas entidades federativas del mando que las obligaba a legislar en materia del trabajo, por lo que surge así la Ley Federal del Trabajo, del 18 de Agosto de 1931.

\subsection{Ley Federal del Trabajo de 1931}

Como ya se refirió, a partir de la reforma constitucional de 1929, la legislación laboral en su esencia y reglamentación, es de carácter federal, por lo cual en el año de 1931 se dictó por el Congreso de la Unión la primera Ley Federal del Trabajo en el país.

Esta Ley Federal de 1931, concibió a las Juntas de Conciliación y las Juntas de Conciliación y Arbitraje, tanto en el orden local como en el federal; es decir, no obstante que se estaba en presencia de una reglamentación federal que regía en todo el territorio nacional, las autoridades aplicadoras eran tanto federales como locales.

Bajo esta ley las Juntas de Conciliación existieron en dos modalidades: Permanentes o Accidentales; y las Juntas de Conciliación y Arbitraje, también existieron bajo dos modalidades: Las de los Estados, se llamaron Juntas Centrales de Conciliación y Arbitraje, y la Federal, Junta Federal de Conciliación y Arbitraje.

Por lo que respecta a las Juntas de Conciliación y Arbitraje, éstas funcionaban en Pleno o a través de Grupos Especiales, y sus representantes obrero-patronales eran electos por dos años.

3 De Pina, Rafael. Op.Cit. pp. 56 y 57. 


\subsection{Ley Federal del Trabajo de 1970}

A propuesta del Presidente Gustavo Díaz Ordaz, el Congreso de la Unión dictó una nueva Ley del Trabajo, que entró en vigor el 1 ${ }^{\circ}$. de Mayo de 1970.

Esta nueva legislación continuó reglamentando la actuación de las Juntas de Conciliación, en sus modalidades de Permanentes y Accidentales; sin embargo determinó que serían sólo instancias Conciliatorias Potestativas, y que ocasionalmente podrían actuar como de Conciliación y Arbitraje, en los términos del artículo 591 de dicha Ley. No obstante, cabe destacar que el Pleno de la Junta Federal de Conciliación y Arbitraje, acordó suprimir las Juntas Federales de Conciliación, en el año de 1984.

Respecto a las Juntas de Conciliación y Arbitraje, continuaron existiendo tanto a nivel local como federal; empero en el ámbito estatal dejaron de ser Juntas Centrales, para convertirse en Juntas Locales de Conciliación y Arbitraje. $\mathrm{Su}$ integración siguió siendo de carácter tripartita, a pesar de que en su artículo 620 permitió la actuación de ciertas audiencias, a pesar de la ausencia de los representantes obrero-patronales; sin embargo, hubo una modificación en relación a la duración de sus encargos, para pasar a ser electos por seis años. En cuanto a su funcionamiento continúan actuando en Pleno o en Juntas Especiales, desapareciendo los Grupos Especiales, en términos del artículo 606 de dicha Ley Laboral.

Esta nueva reglamentación creó nuevos procedimientos: El Ordinario, El Especial y el de Conflictos Colectivos de Naturaleza Económica. También modificó el procedimiento en material de Huelga, y además introdujo un capítulo al que se le denominó Procedimientos Paraprocesales o Voluntarios.

En dicha legislación se confirma la facultad de las Juntas de Conciliación y Arbitraje-locales y federales- para recibir el depósito los Contratos Colectivos de Trabajo, en términos de su artículo 527. Respecto al registro de los sindicatos, continúan siendo las Juntas Locales de Conciliación y Arbitraje y la Secretaría del Trabajo y de Previsión Social, competentes para el registro de los sindicatos de conformidad con el artículo 365 de esta Ley del Trabajo.

La legislación en comento otorgó facultades a la Secretaría del Trabajo y 
Previsión Social, para crear Juntas Especiales de Conciliación y Arbitraje en las entidades federativas, conociendo sólo de asuntos individuales de su competencia acorde a lo dispuesto en el referido artículo 606.

\subsection{Reforma Laboral de 2012}

Las modificaciones que se hicieron a la Ley Federal del Trabajo en ese año vigentes a partir del $1^{\circ}$. De diciembre, suprimió las Juntas de Conciliación y estableció un término transitorio para el cumplimiento de esa disposición.

En esta reforma, también se modificó la integración del Pleno, de la Junta Federal de Conciliación y Arbitraje, para que ya no formen parte del Pleno, los representantes obrero-patronales de las Juntas Especiales establecidas fuera del Distrito Federal -hoy Ciudad de México-. Lo anterior en términos del artículo 607 de la Ley Laboral.

Por otra parte, se exigió que los Actuarios de las Juntas de Conciliación y Arbitraje -federal y locales-, tener título legalmente expedido de abogado o licenciado en derecho, en términos del artículo 626 de la ley laboral en cita. Asimismo se exigió a los abogados postulantes, incluyendo a los defensores de oficio, para poder comparecer en juicio que acrediten ser abogados o licenciados en derecho con cédula profesional o carta de pasante, de conformidad con los artículos 533 y 692 de esta legislación del trabajo. Finalmente, con esta reforma se crearon los Funcionarios de Carrera y la figura de los Conciliadores, en términos de los artículos 614 fracción I, 617 fracción IX, 627-A y 627-B de la ley laboral.

\section{Diálogos por la Justicia Cotidiana}

Los Diálogos por la Justicia Cotidiana ${ }^{4}$ han señalado que la justicia cotidiana es la justicia más cercana a las personas, es decir, la que vivimos día a día en nuestras interacciones ordinarias, la que facilita la convivencia armónica y la paz social, la que reclaman vecinos, trabajadores, padres de familia y la que se vive

4 Diálogos por la Justicia Cotidiana: https://www.gob.mx/cms/uploads/attachment/file/79028/Di_logos Justicia_Cotidiana.pdf. Presentación. 
en las escuelas.

Afirman también que por décadas la justicia cotidiana ha estado lejos de ser una prioridad en nuestro país, y que nos hemos concentrado en la justicia penal, que aunque es importante, atiende conflictos menos frecuentes.

Por lo anterior, es importante para los fines de este trabajo analizar los orígenes y objetivos de la justicia cotidiana.

\subsection{Antecedentes}

Los Diálogos por la Justicia Cotidiana ${ }^{5}$ señalan que, el pasado 27 de noviembre del 2014, el Presidente de la República, Enrique Peña Nieto, solicitó al Centro de Investigación y Docencia Económicas (CIDE) que estableciera foros de consulta para poder preparar propuestas y recomendaciones para asegurar un mayor y mejor acceso a la justicia. Estos Diálogos por la Justicia Cotidiana, convocados en noviembre de 2015 por el Gobierno de la República, en conjunto con el CIDE y el Instituto de Investigaciones Jurídicas de la UNAM, desarrollaron algunas de las principales recomendaciones y soluciones para los problemas que afectan más frecuentemente a los ciudadanos en materia de justicia cotidiana.

En ese documento se afirma que en los Diálogos participaron más de 200 personas de 26 instituciones de todos los sectores: investigadores y representantes de la sociedad civil, académicos, abogados, representantes de organismos autónomos y diversas autoridades de los poderes ejecutivo, legislativo y judicial, quienes se reunieron durante casi cuatro meses para diagnosticar y generar soluciones para resolver los principales problemas en el acceso a la justicia.

\subsection{Diálogos por la Justicia Cotidiana en la Justicia Laboral}

Para alcanzar sus metas los Diálogos por la Justicia Cotidiana ${ }^{6}$, conformaron nueve mesas de trabajo temáticas con el objetivo de discutir de manera puntual cada

5 MIC No. 23. Presentación

6 MIC. No. 23. Pág. 3 
una de las problemáticas que enfrenta la justicia cotidiana, para posteriormente proponer soluciones para mejorar el acceso a la justicia. Los temas de las mesas fueron: A. Justicia Civil y Familiar. B. Justicia Laboral. C. Medidas para Reducir la Marginación Jurídica. D. Mejora de la Enseñanza y del Ejercicio del Derecho. E. Violencia en las Escuelas. F. Asistencia Jurídica Temprana y Justicia Alternativa. G. Organización y Funcionamiento de los Poderes Judiciales. H. Resolución del Fondo del Conflicto y Amparo. I. Política en Materia de Justicia.

En lo relativo a los problemas de impartición de la Justicia Laboral abarcó el funcionamiento de los tribunales del trabajo -Junta Federal, Juntas Locales y Tribunal Federal-, así como la práctica de litigio inadecuado dentro de los mismos, detectando áreas de oportunidad específicas.

\subsubsection{Problemas específicos}

La mesa de Justicia Laboral ${ }^{7}$ identificó problemas tanto hacia el interior de los tribunales del trabajo, como los que tienen que ver con los justiciables; resultando como problemas detectados los siguientes: A. Desaprovechamiento o uso indebido de la conciliación. B. Falta de modernización y agilización de procedimientos mediante el uso adecuado de tecnologías de información. C. Falta de implementación del juicio en línea. D. Carencia de un órgano de inspección del funcionamiento de las juntas. E. Falta de obligatoriedad a la adopción de criterios por reiteración. F. Deficiencia en la implementación del servicio profesional de carrera. G. Limitación y cuestionamiento a la independencia de las juntas, principalmente en el ámbito local. H. Insuficiencia de mecanismos que promuevan el convenio fuera de juicio. I. Dificultad en la ejecución de los laudos. J. Retraso en la práctica de notificaciones y exhortos. K. Ausencia de un esquema de organización que permita concentrar los recursos humanos y materiales con que se cuenta en las áreas más problemáticas o que demandan mayor atención. L. Insuficiencia administrativa. M. Prácticas de corrupción. N. Retrasos en la práctica de notificaciones y exhortos. Ñ. Burocratización en sus operaciones y excesivas cargas de trabajo por asuntos que no son propios de su

7 MIC. No. 23. Págs. 35 y 36. 
competencia laboral originaria. O. Uso indebido de la conciliación, ya que con cierta regularidad se recurre a los tribunales bajo la idea de lograr una disminución de las obligaciones mínimas legales. P. Simulación de abandono del empleo que pudiera interpretarse como un despido. Q. Despidos injustificados que simulan renuncias $\mathrm{u}$ ofertas de reinstalación del trabajador. R. Abuso del principio de oralidad. S. Ofrecimiento excesivo de pruebas y de los medios de impugnación de los laudos. T. Abuso del amparo. U. Presentación de contratos de protección patronal, sindicatos fantasmas que desconocen los trabajadores V. Demora de los recuentos sindicales para la titularidad de contratos.

\subsubsection{Soluciones propuestas}

Los Diálogos por la Justicia Cotidiana ${ }^{8}$ refieren que como resultado del análisis y diálogo entre los representantes de gobierno, tribunales laborales, academia y sociedad civil, que participaron en la mesa de justicia laboral cotidiana, se arribó a la conclusión de la necesidad de reformar principalmente la Ley Federal del Trabajo, la Ley Federal de los Trabajadores al Servicio del Estado, la Ley Orgánica de la Administración Publica Federal, la Ley Federal de Responsabilidades Administrativas de los Servidores Públicos, el Código Penal, la Ley de Amparo y los Reglamentos Internos de los Tribunales Laborales, mencionando además, expresaron, que a efecto de que este paquete de iniciativas tuvieran una lógica, el listado de leyes era enunciativo mas no limitativo, pudiendo revisarse, inclusive la propia Constitución.

Como consecuencia a lo anterior se propuso las siguientes medidas y soluciones:

A. Uso adecuado de la conciliación: 1. Dotar de atribuciones a los tribunales laborales para intervenir sin necesidad de iniciar un juicio. 2. Implementar un procedimiento prejudicial conciliatorio. De haber acuerdo en las condiciones de reinstalación se concluye el asunto. 3. Agotada la etapa prejudicial sin alcanzar conciliación el procedimiento versará sobre las condiciones de la relación

8 MIC. No. 23. Págs. 43 a 56. 
laboral. 4. Determinación de criterios para lograr el aprovechamiento al máximo de la conciliación como solución e impedir el ineficiente incremento de asuntos que quizás no cuentan con los elementos de un procedimiento y se limitan a una negociación. 5. En los juicios en los que se demande indemnización o reinstalación, la conciliación podrá abarcar estas acciones, sin limitar los derechos del trabajador. 6. Tratándose de convenios de cumplimiento de laudo, no basta la manifestación de la parte actora de haber recibido otras cantidades, sino que deberá ser acreditado fehacientemente. 7. Analizar la posibilidad y conveniencia de generar convenios para el cumplimiento del laudo.

B. Sancionar los casos de simulación de abandono de empleo que simulan despido: 1. Precisar la figura y el procedimiento de abandono. 2. Sancionar efectivamente a quien simula un juicio o comete fraude procesal

C. Sancionar los casos de despido injustificado que simulan renuncia.: 1. Regular los requisitos para la validez a la renuncia. 2. Establecer una pena económica para los empleadores que simulen una renuncia del trabajador.

D. Transparencia en el despido y contratación en el sector público: 1. Establecer políticas claras en el momento de la contratación que llevan a cabo los entes públicos, así como fomentar mecanismos transparentes en casos de despido.

E. Combatir los casos de ofertas de reinstalación únicamente para ocultar un despido injustificado: 1. Establecer una pena económica para los empleadores que simulen un ofrecimiento de trabajo de mala fe. 2. Analizar mecanismos para ampliar y fortalecer el sistema de aviso previo de terminación laboral con el pago de una indemnización. 3. Regular el pago de gastos y costas. 4. Que el ofrecimiento del trabajo no implique reversión de la carga de la prueba.

F. Sancionar a las partes que se conducen con falsedad: 1. Establecer consecuencias procesales, sanciones económicas y delitos especiales en los casos de falsedad tanto de las partes, como de abogados, funcionarios y auxiliares de la 
impartición de justicia para todos los tribunales laborales.

G. Combatir el abuso del principio de oralidad: 1. Establecer un límite de tiempo razonable base para el desahogo de las audiencias y las intervenciones. Éste podría ser extendido en casos extraordinarios. 2. Otorgar facultades a los tribunales para poder desechar incidentes, recursos o promociones notoriamente improcedentes. 3. Privilegiar que se fije la litis por escrito previo a la audiencia.

H. Eliminar el abuso de las pruebas: 1. Establecer mecanismos para que exista un servicio nacional de peritos. 2. Regular la prueba pericial similar a como se hace en amparo (perito oficial y opcional perito de las partes). 3. Que cada parte asuma el costo del peritaje salvo casos excepcionales.

I. Simplificar el proceso para aclarar el laudo: 1.Facultar a los tribunales para aclarar de oficio el laudo.

J. Combatir los casos de extorsión o simulación en emplazamientos a huelga por firma del Contrato Colectivo de Trabajo: 1. Establecer los requisitos de representatividad para contar con sindicatos en las empresas. 2. Prever mecanismos de verificación y/o consulta a los trabajadores, en emplazamientos a huelga por firma de contrato colectivo de trabajo y/o en su depósito.

$\mathrm{K}$. Eliminar los vicios y retrasos en la práctica de notificaciones y exhortos: 1. Establecer reglas claras para privilegiar y dar validez al uso de medios electrónicos para estandarizar el trámite de los procedimientos laborales y las notificaciones con las TICs. 2. Eliminar la discrecionalidad de cada tribunal utilizando las mejores prácticas en el tema. 3. Limitar el número de notificaciones personales.

L. Procedimientos de conciliación en entidades públicas: 1. Evitar fincar responsabilidad administrativa a aquellos servidores públicos que promuevan estrategias de conciliación cuando éstas sean procedentes bajo determinados parámetros o montos. 2. Incorporar la posibilidad de conciliar. 
M. Eliminar el uso de los tribunales como ventanilla administrativa: 1. Rediseñar el procedimiento sumario acorde a la naturaleza de los conflictos de seguridad social, así como, en su caso, la instancia correspondiente. 2. Introducir procedimientos sumarísimos para cuestiones de bajo monto.

N. Propiciar interés de representantes patronales y de trabajadores ante las Juntas de Conciliación y Arbitraje en la emisión de laudos: 1. Fortalecer los requisitos para su elección, participación, profesionalización y su funcionalidad. 2. Establecer mecanismos para privilegiar que los representantes de los sectores acrediten conocimiento jurídico de la materia laboral.

N. Facilitar la ejecución de los laudos: 1. Revisar los mecanismos presupuestales y las facultades de las autoridades, en particular de los tribunales, para priorizar el cumplimiento de condenas y la ejecución rápida de los laudos, e inhiban un indebido ejercicio del gasto. 2. Prever un mecanismo transversal a todas las dependencias de la APF que permita el eficaz y oportuno cumplimiento de los laudos.

O. Mejoras administrativas: 1. Reglamentar la obligación de establecer reingeniería de procesos, sistemas de información y planeación estratégica. 2. Reforzar los requisitos para que se acredite que las personas designadas cumplan con el perfil necesario para un adecuado desempeño del cargo, vinculado con la inclusión de mecanismos en los reglamentos de evaluación de los presidentes y representantes, que aseguren la valoración de su actualización jurídica, productividad, desempeño y calidad de sus resoluciones.

P. Eliminar los vicios en las disputas de Titularidad de Contrato Colectivo: 1. Revisar y mejorar el Procedimiento Especial de Titularidad de Contrato Colectivo y/o Administración de Contrato Ley de forma que se garantice la confiabilidad del mismo y que se respete la voluntad de los trabajadores.

Q. Eliminar los Contratos de Protección: 1. Precisar los requisitos para el emplazamiento a huelga por firma y el depósito de contratos colectivos de 
trabajo, acreditando la existencia y operación del centro de trabajo y que los trabajadores conocen su contenido y lo avalan.

R. Homologar criterios entre las Juntas y Salas: 1. A partir de la Conferencia Nacional de Juntas de Conciliación y Arbitraje, conformar un órgano colegiado con personalidad jurídica que sirva para la aplicación uniforme y obligatoria de criterios en los tribunales laborales.

S. Igualdad de Género: 1. Que la capacitación a los servidores públicos y todas las actuaciones de los tribunales comprendan una perspectiva de género y de derechos humanos. 2. Establecer herramientas o mecanismos para proteger a las personas trabajadoras de todas las formas de violencia y garantizar sus derechos. 3. Incorporar lenguaje incluyente en la normativa y en las actuaciones de los operadores jurídicos.

T. Eliminarnormas obsoletas, violatorias de derechos e ineficaces: 1. Revisar y reformar artículos obsoletos y que han sido declarados inconstitucionales.

U. Servicio Profesional de Carrera: 1. Contar con personal jurídico y administrativo óptimo, preparado y capacitado, con salarios establecidos a partir de tabuladores. 2. Regular o fortalecer los procedimientos disciplinarios, de forma que sean claros, objetivos y estrictos y que sirvan para garantizar que el personal jurídico de los tribunales cumpla cabalmente con su encargo. 3. Promover mecanismos para que el personal jurídico de las Juntas de Conciliación y Arbitraje sea integrado como de confianza, asegurando el respeto de sus derechos laborales en el servicio profesional de carrera que aplique en cada una, contemplando una disposición transitoria que deje a salvo e intocados los derechos adquiridos. 4. Revisar y perfeccionar las causales previstas para la separación del cargo.

V. Generar indicadores: 1. Generar indicadores para evaluar cada una de las medidas propuestas por la mesa. 


\section{Iniciativas del Ejecutivo Federal en Materia Laboral derivado de la Justicia Cotidiana.}

Como resultado de los Diálogos por la Justicia Cotidiana el Presidente de la Republica en fecha 28 de abril de 2012, presentó dos Iniciativas de Reforma, una en relación al artículo 123 apartado A de nuestra Constitución y otra relativa a la Ley Federal del Trabajo.

\subsection{Iniciativa de Reforma Constitucional al artículo 123, Apartado A}

La iniciativa de reforma constitucional del artículo 123 apartado A, después del trámite legislativo correspondiente fue aprobada con mínimas modificaciones y publicada el 24 de febrero del año en curso. En consecuencia para fines del presente trabajo, resulta de vital importancia analizar la exposición de motivos de dicha iniciativa y los puntos medulares de la reforma aprobada.

\subsubsection{Exposición de motivos}

Como referimos anteriormente esta iniciativa tuvo como orígenes, antecedentes y causas generadoras, los estudios y propuestas realizados en los Diálogos por la Justicia Cotidiana, según se desprende de la exposición de motivos de la iniciativa9 en mención:

EXPOSICIÓN DE MOTIVOS

"Los cambios introducidos en la justicia laboral se sustentaron fundamentalmente en el establecimiento de mecanismos para eficientar los procedimientos acortando tiempos para que la justicia sea una realidad, y en la profesionalización del personal encargado de impartirla. No obstante, después de tres años y como resultado de concienzudas evaluaciones y análisis presentados en diversos foros, se arriba a la conclusión que se

9 Sitio Web Oficial del Senado de la República: http://www.senado.gob.mx/sgsp/gaceta/63/1/2016-04-28-1/ assets/documentos/2 INI_EF_Justitica laboral.pdf 
requieren transformaciones cualitativas para que la justicia laboral cumpla su propósito. Una de las más sentidas demandas de la sociedad mexicana es acceder a una justicia cercana, objetiva, imparcial, eficiente, no es un reclamo exclusivo de la justicia laboral, la exigencia se presenta en todo el espectro de las variadas relaciones humanas en conflicto. La justicia penal es un ejemplo muy acabado de ello, a lo largo de años se ha trabajado en un nuevo sistema de justicia penal que habrá de entrar en vigor en unos dias más.

Esta iniciativa está dirigida a acabar con todo espacio susceptible de prohijar inercias, vicios y prácticas que durante el desarrollo de un conflicto laboral dan lugar a la incertidumbre jurídica.

Se debe eliminar todo elemento que convierta a la justicia laboral en lenta, costosa, de dificil acceso y cuestionable, así como combatir la parcialidad, simulación, discrecionalidad y opacidad.

De acuerdo con los resultados obtenidos en la consulta elaborada por el Centro de Investigación y Docencia Económica (CIDE), en preparación de los Diálogos por la Justicia Cotidiana, las modificaciones normativas en la materia no han generado una percepción de cambio significativo.

Desde el punto de vista de la estructura de los órganos de impartición de justicia, la consulta reveló la necesidad de valorar la situación actual de las Juntas de Conciliación y Arbitraje. A decir de los expertos, la revisión de este tipo de impartidores de justicia, debe incluir, entre otros aspectos relevantes, analizar la autonomía y sus formas de integración tripartita.

También debe destacarse el análisis y diálogo que se desarrolló entre los representantes del gobierno, los tribunales laborales, la academia y la sociedad civil que participaron en la Mesa de Justicia Laboral Cotidiana. La culminación de sus tareas permitió identificar propuestas de solución a diversas situaciones comunes y apremiantes que aquejan la justicia laboral.

Incluso, por tratarse de un tema de la mayor relevancia, los integrantes de la Mesa de Justicia Laboral Cotidiana hicieron una declaración conjunta especifica, en el sentido de continuar con el análisis y discusión de los mecanismos que permitan fortalecer y garantizar la autonomía de los tribunales laborales y analizar el sistema de distribución de competencias en materia laboral entre los ámbitos federal y local.

Por ello, esta iniciativa propone una reforma de fondo al derecho procesal del trabajo, a partir de tres premisas fundamentales:

1.- Se propone que la justicia laboral sea impartida en lo sucesivo por órganos del Poder Judicial Federal o de los poderes judiciales locales, según corresponda.

2.- Se propone replantear la función conciliatoria, de manera que constituya una instancia prejudicial a la cual los trabajadores y patrones deberán acudir. Con esta medida se privilegia que los nuevos órganos de impartición de justicia laboral concentren su atención en las tareas jurisdiccionales, propias de su nueva responsabilidad. En tanto, la función conciliatoria estará a cargo de Centros de Conciliación especializados e imparciales, dotados con personalidad jurídica y patrimonio propios, además de que contarán con plena autonomía técnica, operativa, presupuestaria, de decisión y de gestión; mismos que serán organismos descentralizados. Destaca que la iniciativa delinea el nuevo procedimiento 
que se deberá observar en la instancia conciliatoria de manera que resulte eficaz para las partes. Para tal efecto se propone que esta etapa procesal conste de una sola audiencia obligatoria con fecha y hora debidamente fijadas de manera expedita y que las subsecuentes audiencias de conciliación sólo se realicen con el acuerdo de las partes el tiempo que de común acuerdo determinen.

3.- Se propone revisar el sistema de distribución de competencias entre las autoridades federales y locales. De esta manera, con el propósito de fortalecer el ejercicio de las libertades de negociación colectiva y de sindicación, se considera necesario crear un organismo descentralizado de la Administración Pública Federal que tendrá la facultad, entre otras, de atender el registro de todos los contratos colectivos de trabajo y de las organizaciones sindicales, asi como todos los procesos administrativos inherentes a dichas materias. El organismo también tendrá a su cargo la función conciliatoria en el orden federal.

Dada la trascendental importancia del organismo, se propone que la designación de su titular se realice con la participación del Ejecutivo Federal y el Senado de la República, tal y como acontece en la designación de los titulares de otras instituciones nacionales. En este caso en concreto, la presente iniciativa propone que el Ejecutivo Federal someta una terna a consideración de la Cámara de Senadores, la cual previa comparecencia de las personas interesadas realizará la designación correspondiente. Se requerirá el voto de las dos terceras partes de los integrantes de la Cámara de Senadores presentes o durante los recesos de ésta, de la Comisión Permanente para realizar la designación, dentro del improrrogable PRESIDENCIA DE LA REPÚBLICA" (énfasis añadido)

Del contenido de dicha exposición de motivos se patentiza, como ya lo referimos, que los orígenes y causas generadoras de esta iniciativa constitucional, fueron los Diálogos por la Justicia Cotidiana, específicamente la Mesa de Justicia Laboral Cotidiana; sin embargo, por una extraña razón en esta inédita iniciativa, se propuso la transformación de la fracción XX del apartado A del artículo 123 constitucional, por virtud de la cual desaparecen las Juntas de Conciliación y Arbitraje para ser sustituidas por Tribunales Laborales adheridos al Poder Judicial. No obstante, como lo analizamos en aparatados anteriores de este trabajo, en los Diálogos por la Justicia Cotidiana propusieron fortalecer las Juntas de Conciliación y Arbitraje, profesionalizando el personal que las integra, su capacitación, aumento salarial de acuerdo a tabuladores, establecer indicadores para evaluar su actuación, unificar criterios entre las Juntas de todo el país y darles autonomía e independencia económica, pero en ningún momento recomendaron la desaparición de las Juntas de Conciliación y Arbitraje. 


\subsubsection{Reforma constitucional del 24 de febrero de 1917}

La iniciativa presentada por el Presidente de la República en fecha 28 de abril del 2012, relativa a la reforma del artículo 123 apartado A y que denominó Justicia Laboral, consistió en modificar las fracciones XVII, XVIII, XIX, XX, XXI, XXII bis y XXXI del citado precepto constitucional.

En resumen las propuestas contenidas en la reforma aprobada consistieron en lo siguiente: A. Desaparecen las Juntas de Conciliación y Arbitraje. B. Se sustituyen las Juntas por Tribunales Laborales integrados al Poder Judicial Federal y Local. C. Se les fija a estos bajo que principios deben actuar al resolver las controversias. D. Se crea una instancia Conciliatoria, previa a cualquier juicio. E. La función conciliatoria se encomienda a Organismos Autónomos, tanto a nivel local como a nivel federal. F. El Organismo Federal de Conciliación, conocerá además del Registro de Contratos Colectivos y de Sindicatos, así como de los procedimientos que para eso se establezca en la ley. G. Se amplía la competencia federal para que los Contratos Colectivos y los Sindicatos se manejen por la Autoridad Federal, así como conflictos que afecten a dos o más estados, lo relativo a los Contratos Ley y los problemas que surjan por motivo de conflictos de Higiene y Seguridad y de Capacitación y Adiestramiento. H. Finalmente, se modifican todas las fracciones que refieren la Junta de Conciliación y Arbitraje, para sustituirse por Tribunales Laborales.

\subsection{Iniciativa de reforma a la Ley Federal de Trabajo}

El Presidente de la República como ya se mencionó, en la misma fecha que presentó la iniciativa de reforma constitucional, también planteó una iniciativa para reformar siete artículos de la Ley Federal del Trabajo Cabe destacar que a esta iniciativa a diferencia de la constitucional, el Congreso de la Unión no le ha dado el trámite respectivo, es decir, aún no ha sido sometida a discusiones; en un criterio personal, estimamos que esto obedece a que con motivo de la reforma constitucional resulta inminente una reforma completa a la Ley Federal del Trabajo, y la iniciativa presentada se caracteriza por ser una reforma parcial; 
sin embargo, para el objetivo de este trabajo resulta trascendental analizar su exposición de motivos y las propuestas específicas de reforma.

\subsubsection{Exposición de motivos}

Esta iniciativa de la Ley Federal del Trabajo presentada ante la Cámara de Senadores del Congreso de la Unión el 28 de abril del 2016. ${ }^{10}$ Estableciendo en la misma las causas generadoras y propuestas en su exposición de motivos.

\section{“EXPOSICIÓN DE MOTIVOS}

"El pasado 30 de noviembre del 2012, se publicó en el Diario Oficial de la Federación el Decreto por el que se reforman, adicionan y derogan diversas disposiciones de la Ley Federal del Trabajo. Con esta reforma se logró actualizar la normativa en materia laboral en diversos temas para avanzar en la modernización de las condiciones laborales, en beneficio de los derechos y bienestar de los trabajadores, impulsando al mismo tiempo el crecimiento del sector productivo....

...A pesar de estos avances debemos reconocer que en la Reforma Laboral quedaron pendientes por abordar temas relevantes que ameritan una revisión profunda y detallada. En efecto, la reforma laboral incorporó disposiciones para fortalecer la transparencia y rendición de cuentas de las organizaciones sindicales sin que tales modificaciones afectaran los principios de libertad y autonomía sindical.

En consonancia con esta premisa, se considera que ha llegado el momento de fortalecer los mecanismos que regulan tres procesos fundamentales para el mundo del trabajo: 1) el depósito y registro de los contratos colectivos de trabajo; 2) las reglas de emplazamiento a huelga por firma de contrato y 3) las reglas para el desahogo del recuento de los trabajadores, que constituye la prueba principal para dirimir diversas controversias..."

De lo anterior se patentiza que estamos ante la presencia de una iniciativa de reforma parcial a la Ley Federal del Trabajo, lo cual no cumple con las expectativas y alcances de la reforma constitucional del 24 de febrero del año en curso".

\subsubsection{Contenido de la iniciativa del 28 de abril de 2016}

El Presidente de la República presentó una iniciativa de reforma a la Ley Federal del Trabajo, en la cual propuso se reformaran los siguientes artículos: 390, 390

10 Sitio Web Oficial. del Senado de la Republica: http://www.senado.gob.mx/sgsp/gaceta/63/1/2016-04-28-1/ assets/documentos/5_INI_EF_Ley_Federal_Trabajo.pdf 
Bis, 390 Ter, 931, 931 Bis, 931 Ter, 895 de la Ley Federal del Trabajo.

El resumen las propuestas de reforma consistieron en las siguientes modificaciones: A. El Contrato Colectivo ya no será objeto de depósito, sino que cuando sea presentado a la autoridad correspondiente, se iniciará un procedimiento de registro. B. La iniciación de la vigencia del Contrato Colectivo se marca a partir de la fecha en que la Autoridad Registradora declaré procedente al registro. C. No podrá promoverse Emplazamiento a Huelga exigiendo la Firma de un Contrato Colectivo en el lapso comprendido entre la solicitud del registro y el tiempo que se emplee para ello. Asimismo, una vez declarado su depósito, no podrá plantarse una Huelga por Firma de Contratos Colectivos. D. La Solicitud de Registro, será mediante un proyecto del contrato que presente el empleador. E. Cuando los patrones inicien la Solicitud de Registro del Contrato Colectivo, deberán de acompañar una serie de documentaciones que se mencionan en el artículo 390 Bis. La Autoridad Registradora deberá notificar a los trabajadores y solicitarles una información que también se especifica en el precepto ya citado. F. La Autoridad Registradora ya no será la Junta de Conciliación y Arbitraje ni la Secretaría del Trabajo, esta competencia estará a cargo del Organismo Federal de Conciliación. G. Los trabajadores que laboren en el Centro de Trabajo o donde se aplicará el Contrato Colectivo, deberán informar a la Autoridad Registradora que tienen copia del Contrato Colectivo, de los estatutos del sindicato contratante y de la toma de nota de su directiva y, además su conformidad de apoyar la sindicato en la contratación. H. La Autoridad Registradora deberá constatar que la información que debe de presentar el empleador y los trabajadores, está completa y es verídica. I. Para que se autorice el registro se deberá demostrar que por lo menos 20 trabajadores realizan funciones en la empresa y éstas estén contenidas en el Contrato Colectivo y que el $30 \%$ de dicho número de trabajadores apoye al sindicato contratante. J. La Autoridad Registradora, en la propuesta de reforma a la ley no se indica quien será, pero la fracción XXXI del proyecto aprobado sobre el artículo 123, determina que será el Órgano Conciliador Federal. K. Se establecen Reglas Especiales para los Recuentos en Materia de Huelga y Titularidades de Contrato Colectivo. L. Antes de los Recuentos se elaborará un Padrón con los nombres de los trabajadores que puedan participar en el mismo y se da oportunidad para que las partes participen. M. Cuando se determine el 
contenido del padrón, se podrán recibir objeciones, lo mismo que al celebrarse la votación.

Como se evidencia, algunos de los postulados propuestos al Presidente de la República, en los Diálogos por la Justicia Cotidiana, fueron tomados en cuenta para la iniciativa de reforma a la Ley Federal del Trabajo, como es descargar a la autoridad jurisdiccional laboral de la tarea de Registrar Contratos Colectivos y Sindicatos; sin embargo, otras recomendaciones no se tomaron en cuenta, pues uno de los principales postulados de mayor envergadura era el de acercar la justicia a los interesados; y con la reforma constitucional y esta iniciativa de reforma a la Ley Federal de Trabajo, no se cumplió con el mismo, toda vez que al centralizar en una autoridad federal con domicilio en la Capital -mediante una ampliación de competencia-, el Registro de todos los Contratos Colectivos de México y de todas las Organizaciones Sindicales, constituye una falta de respeto a la soberanía de los estados en un afán de centralismo y control por parte del gobierno federal.

Con independencia a lo anterior, y reafirmando que esta iniciativa sería insuficiente para cumplir con el marco legal de la reforma constitucional del 24 de febrero del año, en curso exponemos algunos comentarios y observaciones a la misma: A. Se dificulta la entrada en vigor del Contrato Colectivo cuando ya se encuentra firmado por las partes, toda vez que se cambia el sistema sencillo de depósito, por un Procedimiento de Registro complicado, y sobre todo con requerimiento de datos diferentes a los que contiene el artículo 391 de la ley vigente. B. Hay una confusión sobre lo que es un Contrato Colectivo, que es el pacto que celebran los sindicatos y los patrones para establecer condiciones de trabajo, generalmente diferentes por ser superiores a las que establece la Ley Federal del Trabajo; pues las propuestas de reforma exigen nombre de los trabajadores, antigüedad, puesto que desempeñan, entre otros. Datos que personalizan y no como es el fin del Contrato Colectivo, en cuanto a que sus disposiciones son de carácter profesional y destinados a cualquier trabajador que desempeñe los puestos que son regulados en el Contrato Colectivo. C. El registro del Contrato Colectivo es objeto de múltiples requisitos e intervención de la Autoridad Registradora, desconociendo la Representación Sindical, olvidando que la propia definición de un Contrato Colectivo, refiere como sujetos a uno o varios patrones, 
a uno o varios sindicatos de patrones, a uno o varios sindicatos de trabajadores, pero nunca se exige el nombre de los trabajadores que se representan y que se beneficiarán con el Contrato Colectivo. Esto es, el Contrato Colectivo es una ley y no puede estarse modificando o cambiando cada que ingrese o cause baja un trabajador. D. En cuanto a los recuentos es positivo que se piense en elaborar un Padrón, sin embargo esto sería muy sencillo: la Lista de Raya del Patrón, la Lista de Trabajadores dados de Alta en el Seguro Social, una Constancia de la Autoridad Registradora de la Membresía de los Trabajadores que laboran en el Centro de Trabajo en conflicto; y en todo caso, en los Conflictos de Huelga, el Acta de la Asamblea donde los Trabajadores acordaron ir a la Huelga y donde aparecen sus nombres. Asimismo para mayor precisión, pudiera constatarse la membresía con el Instituto Mexicano del Seguro Social. E. Finalmente pudiera considerarse que hay una franca violación a la libertad sindical y a la libertad de afiliación de los trabajadores; pues existe una intromisión del estado en la conformación de las condiciones de trabajo, que en principio sólo corresponde a las partes. Es decir, a la Autoridad Registradora Representante del Estado, tan sólo debe constreñirse a constatar que no se contradiga la ley y garantizar el cumplimiento del contrato.

\section{Conclusiones}

Primera: Los Diálogos por la Justicia Cotidiana surgen con motivo de la solicitud realizada por el Presidente de la Republica, Enrique Peña Nieto, el 27 de noviembre de 2014, al Centro de Investigación y Docencia Económicas (CIDE) que estableciera foros de consulta para poder preparar respuestas y recomendaciones para asegurar un mayor y mejor acceso a la justicia. Estos Diálogos convocados en noviembre de 2015 por el Gobierno de la República en conjunto con el CIDE y el Instituto de Investigaciones Jurídicas de la UNAM, desarrollaron recomendaciones y soluciones para los problemas que afectan más frecuentemente a los ciudadanos en materia de justicia cotidiana.

Segunda: Como resultado de los Diálogos por la Justicia Cotidiana el Presidente de la Republica en fecha 28 de abril de 2012 presentó dos iniciativas de reforma, 
una relacionada al artículo 123 apartado A de nuestra Constitución y otra relativa a la Ley Federal del Trabajo.

Tercera: La iniciativa de reforma constitucional del artículo 123 apartado A, después del trámite legislativo correspondiente fue aprobada con mínimas modificaciones y publicada el 24 de febrero del año en curso.

Cuarta: A pesar de que los orígenes y causas generadoras de esta reforma constitucional, fueron los Diálogos por la Justicia Cotidiana, específicamente la Mesa de Justicia Laboral Cotidiana; sin embargo por una insólita razón en esta inédita reforma, se propuso la transformación de la dogmática fracción XX del apartado A del artículo 123 Constitucional, por virtud de la cual desaparecen las Juntas de Conciliación y Arbitraje para ser sustituidos por Tribunales Laborales adheridos al Poder Judicial. Lo anterior no obstante de que como quedo patentizado, en los Diálogos por la Justicia Cotidiana se propusieron entre otras cosas fortalecer las Juntas de Conciliación y Arbitraje, profesionalizando al personal que las integra, su capacitación, aumento salarial de acuerdo a tabuladores, unificar criterios entre las Juntas de todo el país, darles autónoma e independencia económica; inclusive se propuso fortalecer los requisitos para la elección de los representantes obrero- patronales.

Quinta: La iniciativa de reforma a la Ley Federal del Trabajo presentada el 28 de abril de 2016, a diferencia de la Constitucional, el Congreso de la Unión no le ha dado el trámite respectivo, es decir, aún no ha sido sometida a discusión; en un criterio personal, estimamos que esto obedece a que con motivo de la reforma constitucional resulta inminente una reforma completa e integral a la Ley Federal del Trabajo, ya que la iniciativa presentada se caracteriza por ser una reforma parcial. Esto es, resulta insuficiente para una adecuada reglamentación de los alcances y objetivos instaurados en la reforma constitucional del 24 de febrero del año en curso.

Sexta: Algunos de los postulados propuestos al Presidente de la República, en los Diálogos por la Justicia Cotidiana, fueron tomados en cuenta para la iniciativa 
de reforma a la Ley Federal del Trabajo, como es descargar a la autoridad jurisdiccional laboral de la tarea de Registrar Contratos Colectivos y Sindicatos; sin embargo, otras recomendaciones no se tomaron en cuenta, pues uno de los principales postulados de mayor envergadura era el de acercar la justicia a los interesado; y con la reforma constitucional y esta iniciativa de reforma a la Ley Federal de Trabajo, no se cumplió con el mismo, toda vez que al centralizar en una autoridad federal con domicilio en la Capital -mediante una ampliación de competencia-, el Registro de todos los Contratos Colectivos de México y de todas las Organizaciones Sindicales, constituye una falta de respeto a la soberanía de los estados en un afán de centralismo y control por parte del gobierno federal.

Séptima: Consideramos que para que pueda hacerse efectiva la Reforma Constitucional del 24 de febrero del año en curso se requiere un cúmulo de reformas adicionales, entre otras, a la Constitución General de la República artículos 94 y 104-, Constituciones de los Estados, Ley de la Administración Pública Federal, Leyes de Administración Pública locales, Leyes Orgánicas del Poder Judicial Federal y de los Poderes Judiciales Locales y a la misma Ley Federal del Trabajo.

Octava: Finalmente estimamos que en la inminente Reforma a la Ley Federal del Trabajo, se conserven las características sui generis de la jurisdicción laboral, ya que si bien es cierto el Derecho Mexicano vive una verdadera revolución en los tópicos de la Oralidad, los Métodos Alternos y al mismo Control Difuso; estos dos primeros se encuentran regulados aunque sea de manera precaria, pero efectiva en la Ley Laboral desde el año de 1931, siendo la primera Ley en el país en regular estas instituciones; y en relación al Control Difuso, desde mi muy especial punto de vista, tuvo su epicentro en la materia laboral al establecerse en sus inicios que los Convenios Internacionales se encontraban por encima de la Leyes Federales. Por tal motivo, sugiero que en la imperioso Reforma a la Ley Federal del Trabajo, no se trate de emular al resto de las materias, en relación a dichas temáticas, sino que se aproveche esta oportunidad para perfeccionar estas características sui generis de la jurisdicción laboral, que si bien han sido efectivas en todo este tiempo, pueden ser la oportunidad tan esperada, para adecuarlas a 
los tiempos modernos y estar en aptitud de alcanzar una justicia laboral plena.

\section{Bibliografía}

De Pina, Rafael. Curso de Derecho Procesal del Trabajo. Botas, México, 1952.

Rocha Bandala, Juan Francisco y Franco, José Fernando. La Competencia en Materia Laboral. Cárdenas, Editor y Distribuidor, México, 1975. Direcciones electronicas

Diálogos por la Justicia Cotidiana: https://www.gob.mx/cms/ uploads/attachment/file/79028/Di_logos_Justicia_Cotidiana.pdf. Presentación.

Sitio Web Oficial del Senado de la República: http://www.senado.gob. $\mathrm{mx} / \mathrm{sgsp} /$ gaceta/63/1/2016-04-28-1/assets/documentos/2 INI EF Justitica laboral.pdf

http://www.senado.gob.mx/sgsp/gaceta/63/1/2016-04-28-1/assets/ documentos/5 INI_EF_Ley_Federal_Trabajo.pdf

\section{Legislaciones}

Constitución Política de los Estados Unidos Mexicanos.

Ley Federal del Trabajo de 1931.

Ley Federal del Trabajo de 1970.

Ley Federal del Trabajo de 1970 con la reforma del 2012. 